\title{
A STUDY ON ORIGINS AND INCIDENCE OF SPORT-RELATED INJURIES AND POSSIBILITIES FOR PROPHYLAXIS IN BULGARIAN ELITE KARATE ATHLETES
}

\author{
Dimitar Zagorsky
}

National Sports Academy "Vassil Levski”, Sofia, Bulgaria

\begin{abstract}
Introduction: Sport-related traumatism is a major obstacle in the development of athletic mastery and has the possibility for a long-term negative impact on the health of all involved. Karate, as a confrontation on full contact, is expected to predispose its participants to certain injuries, therefore one of the main concerns for doctors in the field of sports medicine will be the prevention of injuries.

The aim of this study is to reveal the relationship between the factors for emergence and progression of sport-related injuries, gained in either training sessions or competitions, in our elite Karate fighters of both sexes and formulate recommendations for possible reduction of the most serious among them.

Methods and methodology of the study: A traumatism-based survey formulated and conducted by the author on 22 Elite Bulgarian Shotokan Karate athletes, the results of which are referenced to those of the international Karate competitors derived from literature sources. The survey presented a ground map of traumatism for the Bulgarian competitors, in which the main chosen trait is the anatomical topology of sustained injuries.

Results and analysis: The study confirmed that Karate fighters with lower degree of fighting proficiency and shorter contest experience are more likely to sustain self-inflicted injuries as a result of weaker dynamic muscle stabilization while performing an attack. The resulting increase in injuries in 1 to 3 Kyu fighters is mainly explained by the increase in fighting confidence compared to the elite Karate contestants. While executing the technique the player should seek more of the control than the combat effectiveness of his attack - a critical step in the development of fighting behavior and proper competitive training of our most promising 1-3 Kyu Karate athletes.
\end{abstract}

Key words: Sport Injuries, Karate Shotokan, Prophylaxis

\section{INTRODUCTION}

Sport-related traumatism is a major obstacle in the development of athletic mastery and has the possibility for a long-term negative impact on the health of all involved if the specificities of the chosen sport in terms of athletic pressure and set goals are underestimated. For many international researchers' sports injuries are considered to be one of the most common forms of traumatism in modern Western society and for many of the older authors Karate is exemplary for a high traumatic risk sport $(\mathrm{Fu}$, Stone, 1994; Soderberg, 1997). Such regressive attitude is related to the fact that Karate, as a confrontation on full contact, should predispose its participants to certain injuries, therefore one of the main concerns for doctors in the field of sports medicine will be the prevention of injuries, hence the importance of prevention and treating these problems in all sports categories as early as possible (McLatchie, 1981, Tenvergert, 1992; Kujala, 1995).

According to Dagorov M.D., sports trauma is "the injury sustained during sports activities" and sports traumatism is "the aggregate of traumatic injuries received by participants in a sports society for a certain period of time" (Dagorov, 2006). Thus, according to our own specialists and international sports medicine specialists, the treatment of sports injuries will be a medical challenge, time consuming and costly, hence the assessment of new injuries and the creation of preventive measures and strategies will be of great scientific, medical and economic importance (Shotorbani, 2012).

Based on international experience as a start point, is highlighted the fact that although injuries are more common in competitive mode, many authors note that serious injuries in competitive Karate are generally rare (Johannsen, Norregaard, 1986; Kujala, 1995; Trojanowski, 1987). According to McLatchie’s observations, some form of impairment occurs on average once every four matches, and disabiliting injuries (sufficient for a contestant to withdraw from the competition) occur once every ten matches (Mc- 
Latchie, 1981). It is interesting to note that at the time of publishing of that scientific paper, the average duration of a Karate bout was only two minutes, from which was derived the proportion of serious injuries as $5 / 100$ minutes of active fighting within the two World Karate-Do Championships observed (19771980 ). As such this retrospective study revealed only 24 serious injuries in 2762 duels (8.7/1000 clashes), or $0.32 / 100$ minutes of active combat.

The contribution of our contemporaries is greatly valued-Arriaza and assoc., reported a total of 497 injuries with an average frequency of 0.18 injuries/ bout (Arriaza, 2009). The rates of total disability in both sexes are divided into categories with a slight curb towards men, with severe injuries grouped and represented by 64 in total. So, the data depicts the fact that even when we have an overall reduction in the percentage of injuries/100 minutes of a match, it will be at the expense of a visible increase in more serious injuries. The explanation is the extra score offered under the new rules when a skillful combination of kicks and sweeping techniques is executed, leading to more frequent use by contestants. These techniques are far more likely to lead to more severe injuries as a result of the greater energy of the body segments involved in the impact and the related possibility of losing control over the applied force. A higher occurrence of injuries is marked (both with higher percentage) among the lighter categories (below $60 \mathrm{~kg}$ in men-0.56/100min, and below 53 $\mathrm{kg}$ in women- $0.42 / 100 \mathrm{~min}$ ), with punches (737 or $82.7 \%$ ) being the cause for more injuries than kicks $(75,7.3 \%)$. The work of Stricevic et al. confirms that punches have a higher injury rate than kicks, due to the fact that the number of punches in competitive Karate is much higher than the number of attacks with the lower limb (a ratio of close to 10:1) (Stricevic, 1983). The next most frequent injuries are in the areas of the face $(646,72.5 \%)$, followed by the head $(103,11.6 \%)$, and lower limbs (57, 6.4\%). The reported injuries were mainly represented by contusions (448, 50.3\%), nosebleeds (144, 16.2\%), and muscle tears (122, 13.7\%), followed by concussions $(34,3.8 \%)$ and joint sprains $(31,3.5 \%)$.

Here, we will deliberately address the gender differences in the distribution of traumatism among international competitors. Never less that we make an assumption that serious injuries are rare, the presentation of a modern and gender-balanced traumatic profile in Karate should also analyze the injuries in Karate Shotokan female fighters. It is evident that competitive Karate is associated with a relatively low rate of serious injuries, although medical care was required in one out of every three bouts, it was mostly for minor injuries. Our own experience, in the face of Zdravko Stefanov, with regard to injuries of the lower extremities, involves female football players: more than $64 \%$ of the injuries received are related to muscle traumas (Stefanov, 2009). Adding 16\% of joint damages, even without taking into account fractures (4\%), LMS (loco-motion system) accounts for $4 / 5$ of the total injuries of the experimental group of elite football female players. In both sports, the key role of the coach is emphasizing the importance to the athlete, of creating specialized and balanced combinations of techniques for warming up the most traumatized muscle groups, then executing them in daily routines. A miss on the target is risking a fall on the attacking side: falling on the back is a risk for head trauma or concussion, or injury due to straining the involved muscle groups.

\section{Aim of the study}

The aim of this study is to reveal the relationship between the factors for emergence and progression of sport-related injuries, gained in either training sessions or competitions, in our elite Karate fighters of both sexes, create guidelines and give recommendations for possible reduction of the most serious among them.

\section{METHODOLOGY}

A traumatism-based survey formulated and conducted by the author on 22 Elite Bulgarian ShotokanKarate athletes, the results of which are referenced to those of the international Karate athletes derived from literature sources. As such the survey presented a ground map of traumatism for the Bulgarian competitors, in which the main chosen trait is the anatomical topology of sustained injuries. Other factors build in the survey, in relation to the prospected connection between the localization of the injury, are: the type of injury (according to the structural impairment) and severity, mechanism (according to the presence or absence of contact with an opponent as cause of the trauma) are divided into direct and non-direct, time (depending on the type of athletic activity-in training or in tournament, when the injury was received).

As doing so we will observe the accepted classification of injuries based on international guide-lines, as: ac- 
cording to the region will split in four generalized areas: injuries to the head, face and neck (including nose, eyes, mouth, mandible, skull); body and genitals (abdomen, chest, back); upper limbs (shoulder, arm, elbow, forearm, wrist, palm and fingers), and lower limbs (thigh, knee, shin, ankle, and foot). According to the type of injuries, the statistical grouping is as follows: hematomas, soft tissue tears, edema and muscle tears, fractures, dislocations, and concussion. According to Macan et al., in contest mode, disabilities are divided into three categories in terms of severity, as convened both by the WTF classification for injury classes (Macan et al., 2006):

Class 1: Contestant is injured, yet in condition to continue the competition;
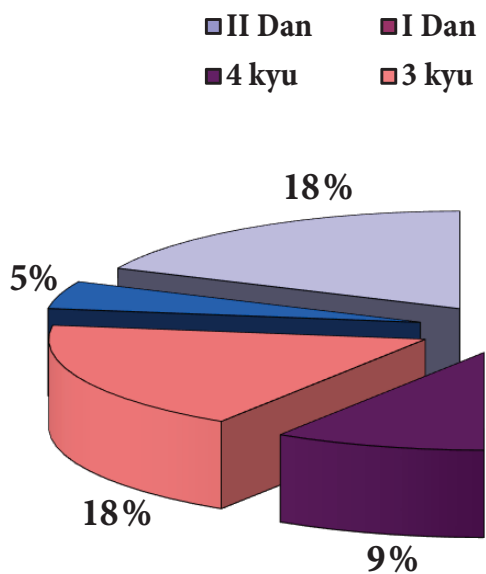

Figure 1. Visual representation of technical proficiency in the study group based on Kyu-Dan level

Using as a starting point the questionnaires from our competitors (Table 1), we derive a greater number of injuries to the lower extremity (18) than to the upper (17). Yet even when there is an equality between the two when comparing overall muscle strains (grade 1 and 2), no matter the complexity of executed fighting technique, there is a marked inclination to injuries of the lower limb for the distal part of the extremities (sustained ankle injury and muscle strain of the toe flexor). Comparing with the international researchers like Arriaza and assoc., which recorded from a total of 497 injuries an average frequency of 0.18 injuries/bout, our own rate is only 46 individual injuries for a total of 256 years of sport practice in our 22 competitors (Arriaza, 2009). Upper limb traumas include fractures of: phalanges (1), and metacarpal bones (3), radial head (1), elbow (1), clavicle (1); dislocated joints: interphalangeal (3), shoulder (1) and elbow (3); subluxated shoulder joint (1), or a total of 15 cases of damages
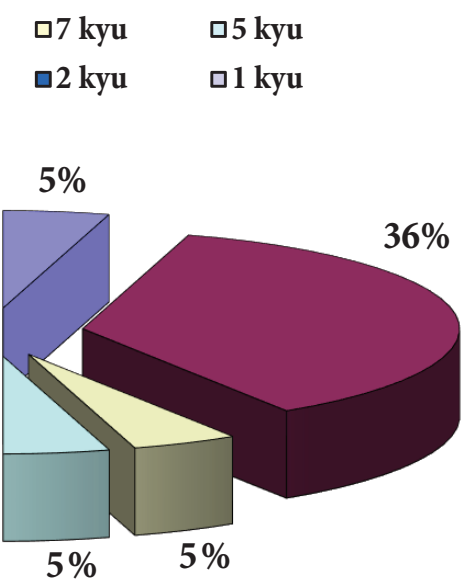

Class 2: Injuries, requiring draw from contest and specialized medical attention or treatment;

Class 3: Injuries, requiring hospitalization.

\section{RESULTS AND ANALYSIS}

In presenting our own Karate competitors, Figure 1 will be informative insofar as it presents the studied karate group as containing a high percentage of high-class competitors (I and II Dan - 41\%), followed by the same percentage in the 1-3 kyu group, illustrating once again the dominance of the high standard (82\%) group of competitors in Karate, and providing measure to the subsequent analysis as relevant to the Elite Karatekas in Bulgaria.

to the LMS. Lower limb injuries were, respectively: phalangeal fractures (1), fibula (external ankle) (1); torn tendons of the: quadriceps muscle class II and III (respectively 3 cases), and thumb flexor (2); injuries at the area of knee (2), talocalcaneal (6) and interphalangeal joints (thumb) (1), or a total of 16 cases. Injuries at the area of the trunk are represented by only 2 cases: rib fracture (1), and pneumothorax requiring withdrawal from the race (1).

Continuing the comparison with Arriaza's analysis, according to the mechanism of sustained injury, punches (335 or 67\%) caused more harm than the kicks (79 or 16\%), while sweeps and falls caused 49 injuries (under 10\%). In the other 25 cases (5\%), the cause was due to other mechanisms (self-injury when twisted ankle or toe while the player was jumping or moving on the tatami). In nine cases (2\%), the mechanism of injury did not fall within the available groups. The author's contribution was the additional focus of our attention to the fact 
that even when only $26 \%$ (128 of 497 ) of the total limbs), which is a favorable trend compared to the number of injuries are caused by the combination gathered literature data (56\%). The sprains are varof sweeping or a kick block, it accounts for 37\% (9 ied - in the upper limb they cover the joints from of 24) of the severe injuries to athletes were caused the elbow to the fingers and appear to be slightly by lower extremity executed techniques.

Combined joint injuries dominate our Karate athletes: sprains and dislocations, as expected, domidominant over the mostly damaged talo-calcaneal joint at the lower extremity. It is interesting that the 1st Dan is always represented within $30 \%$ of all minate (49\% of all injuries on the upper and lower nor injuries of the upper and lower extremities.

Table 1. Adjoined representation of type injuries based on localization and mechanism of sustaining it compared to combatant technical mastership groups;

\begin{tabular}{|c|c|c|c|c|}
\hline \multicolumn{2}{|c|}{ Technical ranking } & I-II DAN & 1-3 kyu & 4-7 kyu \\
\hline \multicolumn{2}{|c|}{ Combat experience } & $13-30 y$ & $4-14$ y. & $1-12$ y. \\
\hline \multirow{6}{*}{$\begin{array}{l}\text { Injuries } \\
\text { Upper } \\
\text { extremity }\end{array}$} & Muscle & $\begin{array}{c}1 \text { Showder blade } \\
\text { muscles }\end{array}$ & $\begin{array}{c}3 \text { Showder blade } \\
\text { muscles }\end{array}$ & - \\
\hline & \multirow[t]{3}{*}{ Joint } & Sprained elbow & Sprained elbow & \multirow{3}{*}{-} \\
\hline & & Sprained wrist (3) & Sprained thumb (2) & \\
\hline & & $\begin{array}{c}\text { Dislocation index } \\
\text { finger }\end{array}$ & $\begin{array}{c}\text { Sprained middle } \\
\text { finger }\end{array}$ & \\
\hline & \multirow[t]{2}{*}{ Bone } & \multirow{2}{*}{ 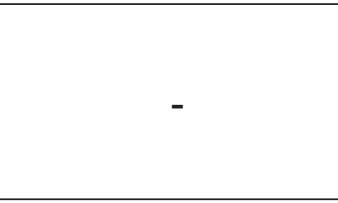 } & $\begin{array}{c}\text { 2: } 1 \text { fract phalanx } \\
\text { index }\end{array}$ & \multirow[t]{2}{*}{ Fracture elbow } \\
\hline & & & $\begin{array}{c}1 \text { Fract carpal } \\
\text { bones }\end{array}$ & \\
\hline \multirow{7}{*}{$\begin{array}{l}\text { Injuries lower } \\
\text { extremity }\end{array}$} & Muscle & $\begin{array}{l}\text { Knee muscles } \\
\text { strain (2) }\end{array}$ & \multirow{2}{*}{ - } & Coxal muscle strain \\
\hline & & Talocalc. Strain (1) & & $\begin{array}{c}\text { Tendo m.flex.haluc } \\
\text { tear }\end{array}$ \\
\hline & \multirow[t]{4}{*}{ Joint } & Sprained knee joint & Ligg.knee joint & \multirow{4}{*}{ 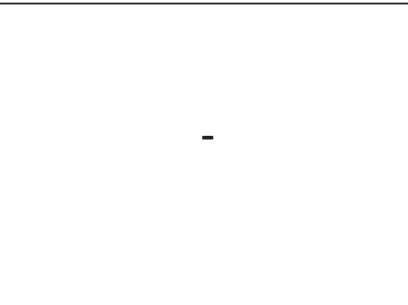 } \\
\hline & & \multirow{3}{*}{$\begin{array}{l}\text { Sprained talocalc. } \\
\text { joint }\end{array}$} & $\begin{array}{c}\text { Sprained talocalc. } \\
\text { joint.(3) }\end{array}$ & \\
\hline & & & $\begin{array}{c}\text { Dislocation talocalc. } \\
\text { joint }\end{array}$ & \\
\hline & & & Dislocated toe (3) & \\
\hline & Bone & - & - & $\begin{array}{c}\text { Fracture toe } \\
\text { Fracture ext. malleoli }\end{array}$ \\
\hline \multicolumn{2}{|c|}{$\begin{array}{c}\text { Head and } \\
\text { Neck traumas }\end{array}$} & - & $\begin{array}{c}\text { Concussion } \\
\text { Soft tissue injuries } \\
\text { Fracture mandibula }\end{array}$ & $\begin{array}{c}\text { Fracture cranium } \\
\text { Nasal bones }\end{array}$ \\
\hline \multirow{2}{*}{ Trunk } & Spine & 1 (Training) & Spinal injury (3) & - \\
\hline & Thorax & - & Fracture ribs 2 & Pneumothorax (surgery) \\
\hline \multirow{2}{*}{$\begin{array}{l}\text { Mechanism } \\
\text { of injury }\end{array}$} & Direct & $\begin{array}{l}\text { Opponent cross (2) } \\
\text { Sustained blow }\end{array}$ & $\begin{array}{c}\text { Direct opponent } \\
\text { hit (5) } \\
\end{array}$ & Sustained blow \\
\hline & Indirect & Loss of balance (2) & $\begin{array}{c}\text { Imprper technique } \\
\mathbf{3} \\
\text { Loss of balance } \\
\end{array}$ & $\begin{array}{l}\text { Improper technique } \\
\text { Loss of balance }\end{array}$ \\
\hline \multirow{2}{*}{\multicolumn{2}{|c|}{$\begin{array}{c}\text { At Contest } \\
\text { Training session }\end{array}$}} & & & \\
\hline & & 4: 2 Sparring & 4: 2 Sparring & 2 Sparring \\
\hline \multicolumn{2}{|c|}{ Sought medical attention } & 4 & 5 & 3 \\
\hline
\end{tabular}


It is noteworthy that in both categories of injuries there is only 1 competitor of high qualification level with chronic complaints in the shoulder or knee joint. Sprains are predominantly represented by those of the distal joints: talo-calcaneal and $1^{\text {st }}$ metatarsophalangeal (4), as well as the knee (2), compared to only 2 of the metacarpophalangeal joints $\left(1^{\text {st }}\right)$, and here the group of 1-3 Kyu fighters stands out as the majority of injured athletes.

If we further apply the experience of our colleagues from Brazil de Souza and his team, we will find that the observed ratio of upper and lower limb injuries in our athletes is not surprising: according to their observations on a larger contingent (53 Shotokan-Karate fighters), of almost 150 injuries in total, the ratio of combined injuries along both the lower and upper extremity is similar-our combined 73\% of LMS traumas is repeated with the approximating $70 \%$ in Brazilian Karatekas (de Souza, 2011). We also have a similar ratio: $37 \%$ versus $33 \%$ injuries to the lower to upper limbs, with similarities even at the level of trauma to the distal parts (foot and hand) ( $18 \%$ in our experience, compared to $13 \%$ in the Brazilian fighters) which, in turn, is explained by the high-profile workload of our elite competitors. All these similarities can be further explained by the similar age category (average age of 22.4 years, beginning their sports career of 14.4 years as an average, with an average of 6.3 years of fighting experience).

Continuing with this set of mind two international teams standout (Zetaruk and Arriaza) for which according to mechanism in more than $40 \%$, damage to the lower limbs is consequence of the miss of the chosen target on the body of the opponent and subsequent muscle strain (33\%), or excessive spin of the limb in one or more of the target joints (46\%) (Zetaruk, 2005; Arriaza, 2005). Our own experience presented only 3 athletes who admitted that their own mistakes in competition (or sparring) caused damage to the lower extremity, marked as hyperextension of muscles around the coxal joint, sprain of both ankle joints and teared tendon of the toe flexor. Even more favorable is the fact that our athletes have derived a balanced ratio between upper and lower extremity muscle strains (3:3). Even more interesting is that in our own athletes there is never a mention of such an uncontrolled kick that results in a high percentage of muscle strains or tendon damages to the thigh muscles (especial- ly the most commonly injured quadriceps muscle, when the kick amiss the fixed target on the opponent's body), let alone having a ratio dominated by muscle hyperextension (5:4), as it is for foreign athletes - for the Bulgarian Karatekas it is 1: $2(6 / 13)$, which by itself is an additional measure for a more balance guided and opponent friendly approach for both fighters.

Compared to the gather data of Bulgarian Karatekas, the picture presented by Zetaruk is even more frightening: due to the fulfillment of the imperative "do not injure the opponent in a bout without need", correlating "interlocked" injuries to the upper and lower limb is illustrated (26 versus $43 \%$, yet even more alarming-shifting to the lower limbs compared to our own more "balanced" injuries of $34 \%$ to $39 \%$ ), especially when leading to injury of the affected joint (Zetaruk, 2005). Our own lower extremity traumatism overlaps with international experience -as expected diverting of an opponent's attack lead to 7 sprains in total of the blocking upper limb (from elbow to wrist and fingers), two dislocations of the metacarpophalangeal joint, and the attacker suffered 4 sprains and dislocations of talo-calcaneal joint of the intercepted foot and another 2 of the metatarsophalangeal joints, accompanied by 2 fractures (one of external malleoli hit by a block with the elbow, and one of crossed thumbs). When assessing fractures, no representatives from the Dan category are ever found, and also in the group 4th to $9^{\text {th }} \mathrm{Kyu}$ (7th Kyu is one of our most traumatized competitors with less than 1-year experience in Karate Shotokan), with only one exception in the group of 1-3 kyu.

All of the above shows that even in competition, and even more visible in sparring, our Karatekas spare their opponents and do not "tax" their LMS, risking their own and others' health. Even more interestingly, an equal number of them (3) recognize that the cause of the injuries sustained in the upper limb section is due to a mistake in their own technique, or because of loss of balance (i.e. self-inflicted injury).

Complementing the detailed picture of sports injuries, we can again turn to the international experience of two teams (Arriaza and Critchley) presenting us with combined head and CNS traumas (18), where the II and III degree concussion (12 and 6 , respectively) are predominant, involvement 
of the cervical spine with transient hemiparesis (1), fracture of the nasal bones (7), and mandible (2), injury to the trachea (1), skin injuries requiring surgical suture (11), or a total of 33 cases (Arriaza, 2009). Not surprising, after the most frequent of injuries-concussions ( 241 or $47 \%$ ), are the injuries in the area of the head-bleeding from the nose (epistaxis) (98 or 20\%), and partial of the cases of lacerated wounds (of the scalp) (52 or 10\%). Thus, among moderate and severe injuries, as many as $56 \%$ are located in the region of the head, with cerebral contusion being among the rarest (18 of 497 injuries or $1 / 153$ battles). Compared to the international experience, our own data outline an interesting trend: in terms of head/facial injuries and such of CNS, only two Bulgarian competitors stand outthe already presented 7 Kyu Karate fighter and the only 1 Kyu competitor (who has suffered a concussion and polytrauma of face and skull, combined with sustained injuries of the spine).

Thus, our respectful $15.6 \%$ of CNS injuries related to the general traumatism of the presented group of elite Karate fighters are at the lower end or can even argue that Bulgarian Karatekas are extremely spared from this type of trauma (depending on the criteria set). Using Arriaza's tournament experience, out of 800 total injuries in two consecutive World Championships, severe CNS damage ranged between 3.3 and $3.6 \%$. Although it is a complex picture containing grade II and III brain concussion and spinal injuries, it presents an alarming trendout of 37 to $45 \%$ of all traumatic injuries sustained by international ranked fighters are CNS related. And if in this researcher's data the absolute combined injuries are only 2 (in a set of 800 bouts), our experience has presented a single competitor $1 \mathrm{Kyu}$ and 10 years of experience (from only 22 participants throughout their sports careers totaling up to 256 years of combat experience), which puts us in the lower end of traumatic CNS injuries.

The classical ratio according to Stricevic indicates that out of every three injuries to the head and neck, two are accompanied by epistaxis, adding that concussions account for as much as $34 \%$ of serious injuries (Stricevic, 1995). Thus, a particularly unfavorable ratio of $6 / 1$ was pointed out by our Serbian colleagues: out of every 6 injuries sustained in a contest, there would be at least one trauma to the skull and/or spine. Our experience has shown that our Karatekas are much more controlled while in our competitors we have only 1 single fracture of all 6 traumas affecting the head and neck region. This shows that any attack that penetrates beyond the competitor's block and leads to severe soft tissue injury (epistaxis) has the potential to cause some form of CNS injury. Unfortunately, both authors recognize the contestants' choice to consciously direct strong and rapid kicks and punches to the opponent's head in search of maximum points. All factored in-punches aimed at the neck or head are the most frequent and high scoring and $85 \%$ of the respondents prefer to choose this technique with their hands aimed at the head for the last point won.

As a consequence, it can be assumed that, in the case of high-ranking fighters, blocking might be fast, yet the combination of short distance, mixed combat techniques, the possibility of loss of control over the attacking limb when the lesser ranked opponent underestimate proper distance increases the risk from suffering unintended injuries to the head. Thus, in Bulgarian Karate athletes there is a more favorable correlation between traumas in the region of head/face accompanied by soft tissue injuries and nose bleeds even more pronounced, with only three of our five injured in this area reporting bleeding with subsequent need of medical attention. As the most common reason is reported a clash with an opponent throughout a tournament, with only one instance -while sparring with a partner due to their own improper technique (delayed block of an attack).

In terms of back/spinal injuries, only two of the polytraumatized fighters featured in our study stand out: 1st Dan (accompanied by injuries to both upper and lower extremities), and the already made as an example for multiple injuries $1 \mathrm{Kyu}$ athlete (12 years of sports experience). While referring to trunk traumas, despite the experience of our international colleagues (Arriaza, 2005), kicks account for only $16 \%$ of sustained injuries, yet they are the "culprits" behind of two inflicted injuries (of all 800 bouts), presented with a single broken rib, and the even more severe abdominal blunt trauma with disqualification and hospitalization. Compared to our own experience with only two competitors with chest injuries: broken ribs (2) (3 kyu), and pneumothorax $(7 \mathrm{kyu})$. However, the picture becomes even more representative, adding both Karate fighters with spinal injuries, with our own athletes marking the staggering $9 \%$ of all injuries 
to be localized in the spine/chest region, and even worse-injuries falling under the the severe category. It should be noted that spinal cord trauma affects only one of the Karatekas 1st Dan, and is sustained in training, not competition.

This high percentage (based on only 22 participants in our study) is a reason for coaches to pay serious attention about the importance of both the combination of proper warming up, maintaining fine spinal muscle tone, as well as the risks in execution of extremely powerful techniques (round kicks) which result in the loss of visual contact with the opponent, who can literally "put" himself on the attacker's leg and make the kick extremely traumatic.

Regardless of the detailed picture of traumas, it will not be complete without paying attention to the gender differences in the distribution of injuries among international athletes and compare to our own data. Although it is based on the assumption that serious injuries are rare, the formation of a modern and gender-balanced traumatic profile in Karate requires also to incorporate the injuries in female Karate fighters.

Referring to the work of Halabchi et al, there will be considerable clarity through the analysis of possible predisposing factors, the frequency of injuries and patterns of injury in Iranian female competitors. They reveal surprisingly similar mechanism and localization of injuries within three consecutive World Karate Championships (1996-2000), marking a steady decline in the number of serious injuries (Halabchi, 2007). Zetaruk adds an even more representative picture involving 1019 athletes (at a frequency of $0.163 /$ match, or 183 injuries/1000 athletes), representing 186 individual injuries from a total of 1,139 bouts (but for both genders), with a more "female-friendly" injury ratio (3:1-men: women) (Zetaruk, 2005). Regardless of gender differences, women have the same injuries in the expected areas: head and neck (55.4\%), lower (21\%), and upper extremities (12.9\%) and trunk (10.8\%). Punches $(48.4 \%)$ dominate again and are associated with more severe injuries than kicks (33.3\%). Traumas are represented by: muscle strains (31\%) and joint dislocations (43.6\%), with $43.6 \%$ of cases in both categories involving the lower extremity- an inevitable result of bal- listic acceleration of the leg when performing a kick (especially if there was no adequate warming up).

Of interest is the work of Macan et al., also focused on gender differences in the traumatic profile of a Karate fighter (Macan, 2006). For the selected championships in 1997 and 2002, despite the increasing duration of aggregate matches (2584 $\mathrm{min}$ in 2002 compared to $2023.5 \mathrm{~min}$ in 1997), the overall percentage of injury frequency is fairly similar ( 9.82 versus $10.28 / 100$ min per duel). The leg is often injured in both rivals when one is simultaneously attacked by and blocks with a kick. It is reassuring that for both Championships, over $98 \%$ of injuries are Class I injuries so opponents can continue the tournament and are affecting both sexes equally. In 1997, only 5/208 injuries were categorized as Class II, compared to marked decrease in 2002only $2 / 254$ injuries were Class II, and only one case in Class III - fracture of the cheek with a lesion of n.trigeminus, never before in 1997 . There is a favorable trend regarding gender differentiation and traumatic risk in our study group: among female Karate athletes the sustained trauma ratio is $2: 3$, in favor of the high-profile group of I Dan compared to 1-3 kyu, with only 1 female representative having "zero" traumatism (5 kyu with 12 years of combat experience), which goes beyond the represented 2 categories. The sample is of slightly injured female athletes - only 1 example from the 1st Dan group (Kyokushin-Kai with BMI of $38 \mathrm{~kg} / \mathrm{m}^{2}$ and 14 years of combat experience) has multiple injuries: evenly distributed between upper (chronic inflammation of the shoulder joint) and lower extremity (muscle strain of the triceps surae muscle), whereas if we choose to apply the category of severe sports injury (fractures of the ribs and shoulder joint), only two athletes will be identified (not unexpectedly by the group of experienced but still evolving 2 and $3 \mathrm{Kyu}$ female Karatekas).

With the proper emphasis already placed, it is hardly surprising that according to Macan, all class II and III injuries in both periods will mainly affect male athletes (cadets, adolescents and adults), confirming the already established attitude for more frequent injuries among male fighters, confirmed by other authors such as Tuominen and Critchley (Tuominen, 1995; Critchley, 1999). Among our own male contingent (15), all athletes have some form of sports trauma: the ratio between the high-ranking 
kyu-Dan contestants compared to the lesser fight proficient competitors is almost even (7/8). Two representatives of the I-II Dan group are without injuries, and the third is with a spinal injury acquired in training. The other four are I Dan with 13-15 years of experience and multiple injuries. Among the four men in category of 1 kyu there is a nuance: from a single broken phalanx of an index finger (during a clash with an opponent in competitive mode), up to two athletes with 10 and 12 years of combat experience where all four parts of the body are injured. In both of the 3 kyu Karatekas we have practically both extremes: from a single twist of talo-calcaneal joint in a competitor with 10 years of experience (minimal damage) to whole body encompassing injuries in the one with 11 years of experience (damages to elbow, wrist/hand joints, knee and ankle injuries strained leg muscles). The 1 and 3 kyu Karatekas thus presented are sufficiently close on level of technical skills to each other to emphasize that the increase in self-confidence and the addition of risky attacks is a factor in which "the pay" for the winning point is disproportionate to the chance of being intercepted or receiving injury. The fact is that only two of the 4 kyu have only marked broken finger and muscle hyperextension, against the background of 6 and 8 years of combat experience.

Using Figure 2, we can easily visualize the general claim that the Bulgarian elite Karate fighters are marked in each selected category of traumas in the lower and thus-favorable values. Therefore, in I-II Dan athletes, there are only isolated cases in tournament where their own decisions were decisive for sustaining the injury, compared to the more common cause for being an aggressive player at a lower technical level. This illustrates that the combination of proper conditioning, fairly played confrontation of both sides (attacker and opponent), led sparingly and with a thought for protection, have a beneficial effect on the frequency of injuries sustained and inflicted on the body during competition and training.

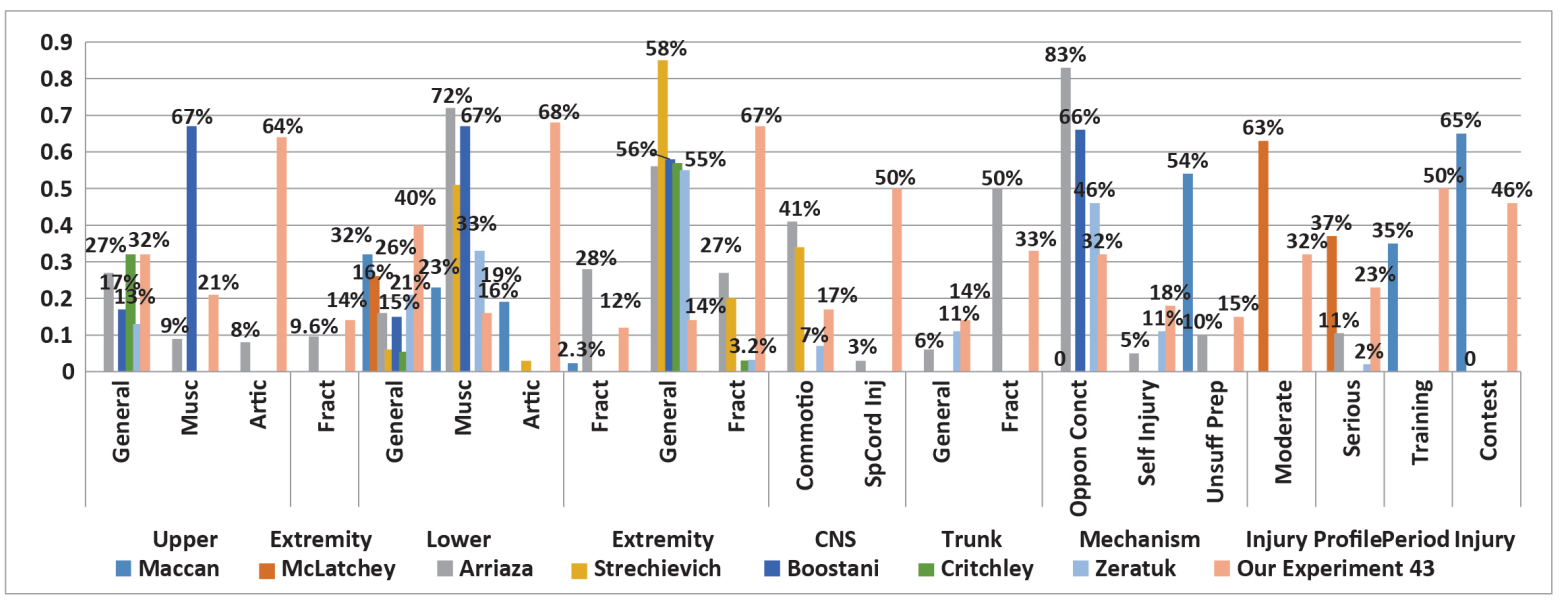

Figure 2. Visual representation of comparative traumatism in study group of Karate athletes compared to international contestants

\section{CONCLUSION}

According to the presented complex analysis Bulgarian Karate fighters lead their respected international counterparts by severity of affected regions and types of injuries. Our own high-ranking athletes maintain a level of proficiency while executing punches, reducing the risk of unintentional trauma to their opponent's head relative to international data. The resulting increase in injuries in 1 to $3 \mathrm{Kyu}$ fighters is mainly explained by the increase in fighting confidence and the choice of performing explosive but also risky attacks, allows for our elite competitors to stand out (from I dan and up), for whom those type of injuries are scarce. The expected dependence that male Karate fighters, and especially those unexperienced and less proficient in combat, were also more likely to sustain of afflict injury to their opponent in a tournament, compared to representatives of the opposite sex.

All this is a reason for serious attention on behalf of the Karate trainers about the importance of the combination of proper warming-up and proper muscle tone exercises in both sexes, yet a critical step in the combat development and prophylaxis of our most promising 1-3 Kyu Karate athletes. The 
introduction and implementation of specialized stretching techniques in the training sessions, especially when adapted to the traumatized muscle groups presented in this study, will be an effective means of controlling the most commonly sustained injuries.

\section{REFERENCES}

Arriaza, R., Leyes, M. (2005). Injury profile in competitive karate: prospective analysis of three consecutive World Karate Championships. Knee Surg Sports Traumatol Arthrosc. Vol.13, pp.603-607

Arriaza, R., Leyes, M., Arriaza, A. (2009). The injury profile of Karate DO World Championships: new rules, less injuries. Knee Surg Sports Traumatol Arthrosc. Vol.17, pp.1437-1442

Critchley, G.R., Mannion, S., Meredith, C. (1999). Injury rates in shotokan Karate. Br J Sports Med; Vol.33, pp. 174-177

Dagorov, N. (2006). Sport without traumas. PPA. Dimi Style, Sofia

de Souza, J.M.C., Faim, F.T., Nakashima, I.Y., Altruda, C.R., Medeiros, W.M., da Silva, L.R. (2011). Lesions in Shotokan Karate and Jiu-Jitsu - direct trauma versus indirect. Rev Bras Med Esporte. vol.17, no.2, DOI: 10.1590/ S1517-86922011000200007

Fu, F., Stone, D., (1994). Sports injuries. Williams\&Wilkins, Baltimore

Halabchi, F., Ziaee, V., Lotfian, S. (2007). Injury profile in women Shotokan Karate Championships in Iran (20042005). J Sports Sci Med; Vol.6, pp. 52-57

Johannsen, H.V., Norregaard, F.O. (1986). Karate injuries in relation to the qualifications of participants and competition success. Ugerskr Laeger, Vol.148, pp.1786-1790 Kujala, U.M., Taimela, S., Antti-Poika, I. (1995). Acute injuries in soccer, ice hockey, volleyball, basketball, judo and karate: analysis of national registry data. $B M J .311$ pp.1465-1468

Macan, J., Bundalo-Vrbanac, D., Romić, G. (2006). Effects of the new karate rules on the incidence and dis- tribution of injuries. British Journal of Sports Medicine Vol.40 (4), pp.326-330

McLatchie, G.R. (1981). Karate and karate injuries. Br J Sports Med, pp. 1584-1586

McLatchie, G.R., Commandre, F.A., Zakarian, H., et al. (1994). Injuries in the martial arts. Renstrom P, ed. Clinical practice of sports injury: prevention and care. Oxford: Blackwell, pp.609-623

Shotorbani, F.N., Mohammad, H., Jadidi, R., Rasuli, S., Neshati, A., (2012). Prevalence of sports injuries in elite female karate athletes (Ahar, Iran). Annals of Biological Research, Vol.3 (1), pp.445-450

Soderberg, G., (1997). Kinesiology - application to pathological motion. Williamse Wilkins, Baltimore

Stefanov, Zdr., (2009). A study of sport traumatism and trends in training process leading to better prophylaxis for the female football athletes. (dissertation)

Stricevic, M.V., Patel, M.R., Okazaki, T., Swain, B.K. (1983). Karate: historical perspective and injuries sustained in national and international tournament competitions. Am J Sports Med.Vol.11, pp.320- 324

Tenvergert, E.M., Ten Duis, H. J., Klasen, H.J. (1992). Trends in sports injuries, 1982-1988: an in-depth study on four types of sport. J Sports Med Phys Fitness, Vol.32, pp. 214-220

Trojanowski, D. (1987). Injuries during karate competitions. Identification of risk groups. Lakartidningen, Vol.84, pp.1858-1860

Tuominen, R. (1995). Injuries in national karate competitions in Finland. Scand J Med Sci Sports. pp.544-48

Zetaruk, M.N, Violan, M.A., Zurakowski, D., Michaeli, L. J. (2005). Injuries in martial arts: a comparison of five styles. British journal of sport medicine, Vol.39, pp. 29-33

Corresponding author: Zagorsky Dimitar, PhD, MD Anatomy and Biomechanics Department National Sports Academy "Vassil Levski" Sofia, Bulgaria 1710, Studentski grad, bl. 70 E-mail: dimzigzag_solo@yahoo.com 